\title{
The Degree of the Application of the Jordanian Physical Education Curricula in Light of the Relevant Jordanian Standards from the Viewpoint of the Teachers in the Northern Governorates of Jordan
}

\author{
Dr. Jumana Faleh Muhammad Al-Atoom ${ }^{1} \quad$ Prof. Abdul Salam Jaber Hussein ${ }^{2}$ \\ 1.The Ministry of Education \\ 2.The University of Jordan / Faculty of Physical Education
}

\begin{abstract}
The study aimed to identify the degree of the application of the Jordanian physical education curricula in light of the relevant Jordanian standards from the viewpoint of the teachers in the northern governorates of Jordan. The current study used the survey descriptive approach. The study sample consisted of the 1st and 2nd-grade teacher guidebook and (79) teachers randomly selected. The data were analyzed using the Statistical Package for the Social Sciences program. The results showed that the degree of application of the physical education teachers in the governorates of (Jerash, Ajloun, and Mafraq) to the six standards was a medium degree from their point of view. Besides, the study showed that the most experienced teachers are the most capable of applying the Jordanian physical education curricula in light of the content of the relevant Jordanian standards compared to Bachelor-degree teachers. On the other hand, there are no differences because of the gender variable in the application of the Jordanian physical education curricula in light of the content of the Jordanian standards from their point of view.
\end{abstract}

Keywords: physical education curricula, standards, northern governorates, Jordan

DOI: $10.7176 / \mathrm{JEP} / 11-4-09$

Publication date: February $29^{\text {th }} 2020$

\subsection{Introduction}

The school curricula contribute to build and prepare the student's personality by providing educational experiences previously designed based on the standards of the Ministry of Education deriving from the educational philosophy of the Jordanian state to keep pace with the rapid developments of life towards the digital world. Through the 2015 educational development conference, the Jordanian Ministry of Education worked on the necessity of updating and developing the educational curricula as a basis for the educational and teaching process to keep them up to date with the new developments on an ongoing basis. One of the most significant justifications for the conference was to keep abreast of various educational developments, develop the elements of the educational learning process, address weaknesses that have emerged through international and national studies on the curricula, and benefit from the experiences of developed countries and local, regional, and international success stories (Educational Development Conference, 2015).

Michael (2017) defines the school curricula as a set of skills, knowledge, and experiences that help students in school learn in light of the outcomes to be achieved, and this requires a well-designed curriculum so that students can achieve and implement them. The physical education curriculum aims to achieve the objectives of general education in terms of preparing youth healthily and physically and guiding them to move towards achieving what is in the interest of society and themselves so that they are effective and good citizens. The physical education curriculum includes a variety of necessary and appropriate motor knowledge and characteristics appropriate to the characteristics and needs of the individual at every age because a healthy individual can use his physical potential positively in different life situations to succeed in his life and fulfill his requirements (Mahrous, 2017). Hussein (2011) asserts that the physical education curricula need to be followed and developed in line with the developments of the modern era in an effective system that achieves comprehensive educational values so that the learner can have an active role in society.

Contemporary physical education curricula are concerned with the learner's tendencies, preparations, and requirements necessary to develop, meet his needs and interests, and improve his mental and physical capabilities through adaptation to the student's environment and concerted efforts to define and formulate the objectives of physical education and design content and activities that translate those goals into reality whose focus is the learner (Palmade, 2001). Abdulbasit (2008) conducts a study aimed at setting academic standards for the content of physical education curricula in the elementary education stage whose most important results are proposing 17 indicators of academic standards for first, second, and third grades, setting academic standards for the goals of the physical education and sports curriculum, and setting academic standards for the content of the physical education and sports curriculum. Harris (2015) also conducted a study aimed at identifying the extent of the interest of physical education curricula with health in secondary stage schools in Britain and Wales. The 
results of the study showed that the curricula are deeply concerned with health, as health is related to fitness, and most activities focus on fitness under the title of expression effect about health in physical education curricula in secondary schools.

In view of the great goals that the physical education curricula aim to achieve in the personality of students, it is essential to pay attention to their evaluation and development in the various academic stages in a manner that is compatible with the scientific and technological development in the world. To achieve this, it is required to analyze the content of the curricula, which will reveal the effectiveness of educational experiences in achieving educational outcomes and identifying weaknesses and strengths in the physical education curriculum. Importantly, this will help teachers implement various activities that suit the inclinations, desires, and capabilities of students, and thus improve their physical, practical, and health level and develop their sports culture (Rao, 2007).

Additionally, Saidi and Hussein (2018) indicate that the concept of modern curricula in the $21^{\text {st }}$ century is represented by a number of aspects such as the knowledge economy linked to intelligence and creativity, time management and investment in the product, as well as life skills that emphasize the requirements of life. Tiffany (2012) conducted a study aimed at assessing physical education curricula from the teachers' point of view. The results of the study showed that their degree of satisfaction with the curriculum was medium, along with the presence of various important challenges facing the curricula such as the lack of effective content and the lack of diversification in activities. The results also showed that trained teachers were the most capable of implement good educational procedures compared to non-trained teachers. The study recommended an increasing focus on activity and the need to support teachers in various courses.

\subsection{Problem of the Study}

The problem of study stemmed from the practical reality of the researcher as an educational supervisor for physical education at the Jordanian Ministry of Education and her strong belief of the need to apply the physical education curriculum for the lower elementary stage being the first developed and officially approved teacher guidebook applied since 2014/2015. Considering this stage is important and the basis for the subsequent stages in learning sports activities and skills, the researcher has selected the first and second grades' guidebooks within the relevant stage to be applied in light of selected local standards to help reveal strengths and weaknesses in it and verify the extent of its appropriateness with local standards in terms of construction and design. Besides, the local standards and the degree of their practical application have not previously been compared in the light of physical education curricula. In light of the researcher's knowledge, and Jordan's reliance only on evidence in teaching physical education, it was necessary to provide specifications and standards with content assisting to talk about quality and ensure that they keep pace with the requirements of the modern era and contemporary trends in teaching physical education.

\subsection{Significance of the Study}

Given the significance of the curricula of physical education for the lower elementary stage in achieving the philosophy of education stemming from the philosophy and goals of society, and its reflection on the children's learning, physical growth, personality and development in a balanced manner, and the development of his skills and abilities, this study has been conducted to study the extent to which physical education curricula are applied in the lower elementary stage in the light of global standards to consider the aspects in which the approved curriculum has met those standards, and in the aspects in which these standards have not been met, which helps in getting a deeper understanding of the curriculum, and thus the ability to review and develop it for the best to keep pace with recent developments. The significance of the study is to deepen the awareness of those in charge of physical education curricula in Jordan of the nature of the relationship between the standards required in the content of physical education curricula for the $1^{\text {st }}$ and $2^{\text {nd }}$ grades in the light of the standards of the Ministry of Education, which reflects positively on the quality of curriculum content design and educating physical education teachers with global standards to be followed when implementing the developed curriculum.

\subsection{Questions of the Study}

According to the research problem, the following two questions are required to be answered:

a. What is the degree of the application of the Jordanian physical education curricula in light of the relevant Jordanian standards from the viewpoint of the teachers in the northern governorates of Jordan?

b. Are there statistically significant differences in the degree of the application of the Jordanian physical education curricula in light of the relevant Jordanian standards from the viewpoint of the teachers in the northern governorates of Jordan according to the variables of gender, years of experience, and academic qualification? 


\subsection{Objective of the Study}

In light of the research questions, the following objectives are required to offer useful answers:

a. To identify the degree of the application of the Jordanian physical education curricula in light of the relevant Jordanian standards from the viewpoint of the teachers in the northern governorates of Jordan.

b. To recognize the statistically significant differences in the degree of the application of the Jordanian physical education curricula in light of the relevant Jordanian standards from the viewpoint of the teachers in the northern governorates of Jordan according to the variables of gender, years of experience, and academic qualification.

\subsection{Limitations of the Stud:}

Human limitations: The study sample consisted of (79) male and female teachers of physical education at the Ministry of Education in the northern governorates.

Time limitations: The study was applied in the period (01/04/2019 to $01 / 05 / 2019)$.

Spatial limitations: Education directorates in the governorates of Jerash, Ajloun, and Mafraq.

\subsection{Methodology and Study Procedures Study methodology}

The two researchers used the descriptive survey approach for its suitability with the study population

Study Population: The study population consisted of all male and female teachers of physical education in government schools associated with the directorates of education in Jerash Governorate (157 male and female teachers), Ajloun Governorate (111 male and female teachers), and Mafraq Governorate (104 male and female teachers) for the academic year (2018 / 2019).

Study Sample: The study sample consisted of 79 male and female teachers who hold a Bachelor's degree in Physical Education and teach the first and second elementary grades as shown in Table (1). Table 1:Distribution of Study Sample Remembers According to the Study Variables

\begin{tabular}{|l|l|l|l|}
\hline Variable & Levels & Frequencies & Percentages \\
\cline { 2 - 4 } & Variable & 11 & \\
\hline \multirow{5}{*}{ Gender } & Male & 68 & 0.14 \\
\cline { 2 - 4 } & Female & 79 & 0.86 \\
\cline { 2 - 4 } & Sum & 20 & 1.00 \\
\hline \multirow{5}{*}{ Acars of experience } & Less than 5 years & 23 & 0.25 \\
\cline { 2 - 4 } & 5-10 years & 36 & 0.29 \\
\cline { 2 - 4 } & More than 5 years & 79 & 0.46 \\
\cline { 2 - 4 } & Sum & 67 & 1.00 \\
\hline & Bachelor & 12 & 0.85 \\
\cline { 2 - 4 } & Postgraduate & 79 & 0.15 \\
\cline { 2 - 4 } & & 1.00 \\
\hline
\end{tabular}

\section{Study instrument}

To achieve the aims of the study, the standards set by the Jordanian Ministry of Education are referred to in its guide titled "General Framework and Public and Private Outcomes for Physical Education for Elementary and Secondary Education Stages, 2013", and some previous studies such as the study of Jarrah (2007), where the number of these standards are (6) that include (41) indicators in their initial form, and they were constructed to analyze the content of physical education curricula for the first and second grades. For the response of physical education teachers to the first and second grades, on the other hand, these standards were reviewed and after a survey of the opinions of specialists, a questionnaire was developed to measure the degree of application of the teachers of the first and second grades for the international standards that consisted in its final form of (46) indicators, as some of the items required more detail to be easy to measure. Also, to verify the significance of the validity and reliability of the study instrument, the following procedures have been followed:

\section{Practical Procedures}

1. Content Validity: To verify the content validity of the study instrument, the study instrument was presented in its initial form to a group of validators and specialists in the fields of physical education, measurement and evaluation, and curricula and teaching at the University of Jordan. Thus, the questionnaire consisted of (46) items in its final form distributed over six standards. To answer the items of the study tool that measures the degree of application of physical education teachers of the first and second grades for the international standards for physical education curricula, a five-degree Likert scale has been approved as follows: strongly agree takes 5 degrees, agree takes 4 degrees, medium agree takes 3 degrees, low agree 
takes 2 degrees, and very low agree takes 1 degree.

2. Instrument reliability: To verify the reliability of the internal consistency of the scale of the degree of application of physical education teachers of the first and second grades for the international standards for the physical education curriculum and its dimensions, the Alpha Cronbach equation was used based on the application data for the pilot sample as shown in Table 2.

Table 2: Pearson Correlation Coefficients for the Instrument and its Six Dimensions

\begin{tabular}{|l|l|l|}
\hline Jordanian Standards & $\begin{array}{l}\text { Reliability of the } \\
\text { Internal Consistency }\end{array}$ & $\begin{array}{l}\text { Pearson Correlation } \\
\text { Coefficient }\end{array}$ \\
\hline $\begin{array}{l}\text { Proficiency in basic motor skills as a basis to perform a } \\
\text { variety of games and physical activities. }\end{array}$ & 0.87 & 0.95 \\
\hline $\begin{array}{l}\text { Understanding motor skills, principles, strategies and tactics } \\
\text { applies to learning and performance in physical activities }\end{array}$ & 0.87 & 0.89 \\
\hline Regular physical sport activity & 0.87 & 0.91 \\
\hline $\begin{array}{l}\text { Physical fitness to maintain a high and continuous level of } \\
\text { health }\end{array}$ & 0.85 & 0.88 \\
\hline $\begin{array}{l}\text { Demonstrate personal and social behavior that respects self } \\
\text { and others }\end{array}$ & 0.85 & 0.89 \\
\hline Values to be gained by students through physical education & 0.91 & 0.94 \\
\hline The total number of scale & & 0.89 \\
\hline
\end{tabular}

It is noted from Table (3) that the value of the reliability of the internal consistency of the dimensions of the instrument ranged from 0.85 to 0.91 , the value of the Pearson coefficient factor for the dimensions of the instrument as a whole was 0.89 , and the values for the dimension of the instrument ranged from 0.88 to 0.95 , and these values indicate the quality of the construction of the questionnaire and its validity for this study. The survey sample has been taken to verify the items and their suitability for the study sample and ensure the period for answering the study tool.

\section{Study Procedures}

The researchers reviewed the educational literature and previous studies related to the subject of the current study, whether the studies aimed at evaluating the curriculum through a questionnaire from the teachers 'point of view, such as a study, Zamim (2012), Jarrah (2007), Hawamdeh (2007), Tiffany (2012), Scherer (2008), and Faraji (2015), or foreign studies that expanded in evaluating the curriculum through curriculum analysis such as Kiborn (2016), Harris (2015), and Backman (2010). With that, the procedures are as follows:

* Determine the number of individuals in the study and sample population after obtaining an important facilitation letter directed from the Deanship of the Faculty of Physical Education at the University of Jordan to the Directorate of Education in Jerash Governorate, Ajloun Governorate, and Mafraq Governorate, where the study sample was randomly selected from all male and female teachers of the Directorate of Education for these governorates for the academic year 2018-2019.

* Verify the significance and validity of the study instrument for the finalization of the tool, where the instrument was used to analyze the content of the physical education curriculum for the first and second grades after making modifications to measure the degree of teachers' application of these standards in physical education lessons in the classroom.

* Apply the study instrument in its final form to the individuals of the selected study sample at the specified date, where coordination was made with the directorates of education of the study sample to meet with the teachers and clarify the purpose of the questionnaire and highlight the importance of answering it objectively.

* Collect and audit questionnaires and statistically process them to answer study questions and come up with appropriate recommendations in light of the results of the study.

\section{Statistical processing}

To answer the study questions, the following statistical processing was used:

* To answer the first question of the study questions, the mean, standard deviations, and ranks for the responses of the study sample members were calculated.

* To answer the second question, a multiple triple-variance analysis and a Scheffe statistical test were used to identify the differences' indications in the responses of the study sample members in the measure of the degree of application of the teachers of the first and second grades for the international standards.

\section{Results Discussion}

Results related to the first study question, which stated "What is the degree of the application of the Jordanian physical education curricula in light of the relevant Jordanian standards from the viewpoint of the teachers in the northern governorates of Jordan? 
Table 3:Mathematical Averages, Standard Deviations, and Ranks for the Degree of Physical Education Curriculum Application from the Viewpoint of Northern Governorate Teachers in Jordan

\begin{tabular}{|l|l|l|l|l|l|}
\hline No & Area & AM & SD & Rank & Degree \\
\hline $\mathbf{5}$ & $\begin{array}{l}\text { Demonstrate personal and social behavior that respects self and } \\
\text { others }\end{array}$ & 3.45 & 0.25 & 1 & Medium \\
\hline $\mathbf{4}$ & Physical fitness to maintain a high and continuous level of health & 3.36 & 0.23 & 2 & Medium \\
\hline $\mathbf{1}$ & $\begin{array}{l}\text { Proficiency in basic motor skills as a basis to perform a variety } \\
\text { of games and physical activities. }\end{array}$ & 2.92 & 0.24 & 3 & Medium \\
\hline $\mathbf{2}$ & $\begin{array}{l}\text { Understanding motor skills, principles, strategies and tactics } \\
\text { applies to learning and performance in physical activities }\end{array}$ & 2.76 & 0.20 & 4 & Medium \\
\hline $\mathbf{3}$ & Regular physical sport activity & 2.75 & 0.23 & 5 & Medium \\
\hline $\mathbf{6}$ & Values to be gained by students through physical education & 2.35 & 0.38 & 6 & Medium \\
\hline The total number & $\mathbf{2 . 9 7}$ & $\mathbf{0 . 1 7}$ & & Medium \\
\hline
\end{tabular}

Table (3) showed that the degree of application of physical education teachers in the governorates of (Jerash, Ajloun, and Mafraq) to the skills and concepts included in the standards of physical education curricula for the first and second grades, in general, was in a medium degree with an arithmetic mean of (2.97) and a standard deviation of (0.17) ). It is noted that the fifth standard "Demonstrate personal and social behavior that respects self and others" ranked first with an arithmetic mean of (3.45) and a standard deviation of (0.25). As for the sixth standard, which is "Values to be gained by students through physical education" ranked last with an arithmetic mean of (2.35) and a standard deviation of (0.38). Based on the results, they can be discussed according to the order of standards according to their order as follows:

Results of the fifth standard which is "Demonstrate personal and social behavior that respects self and others" showed that the degree of application of the physical education teachers in the governorates (Jerash, Ajloun, and Mafraq) to the standard of "Demonstrate personal and social behavior that respects self and others" as a whole was in a medium degree, and this result may be caused by the weak interest of the teacher in this aspect that mainly contributes to forming the student's personality in each lesson of the lessons of the curriculum includes motor activities. As for the results of the fourth standard which is "Physical fitness to maintain a high and continuous level of health", they showed that the degree of application of the physical education teachers in the governorates (Jerash, Ajloun, and Mafraq) to "Physical fitness to maintain a high and continuous level of health" as a whole was in a medium degree, and this result may be caused by the guidebook's interest with a special focus on physical fitness as a primary goal in the physical education class for teachers and necessary to prepare students to participate at the King Abdullah II Prize for Physical Fitness because the teacher sometimes does not adhere to the curriculum in implementing lessons .

The results of the first standard which is "Proficiency in basic motor skills as a basis to perform a variety of games and physical activities" showed that the degree of application of the physical education teachers in the governorates (Jerash, Ajloun, and Mafraq) to the standard of "Proficiency in basic motor skills as a basis to perform a variety of games and physical activities" as a whole was in a medium degree, and this result may be caused by the fact that basic motor skills are a requirement for students at this stage in preparation for the subsequent grades, but the degree of their application did not develop as required .

As for the results of the second standard which is "Understanding motor skills, principles, strategies, and tactics applies to learn and performance in physical activities", they showed that the degree of application of the physical education teachers in the governorates (Jerash, Ajloun, and Mafraq) to the standard of "Understanding motor skills, principles, strategies, and tactics applies to learn and performance in physical activities" as a whole was in a medium degree, and this result may be caused by considering understanding a necessity to apply basic skills in motor skills .

As for the results of the third standard which is "Regular physical sport activity, they showed that the degree of application of the physical education teachers in the governorates (Jerash, Ajloun, and Mafraq) to the standard of "Regular physical sport activity" as a whole was in a medium degree, and the items of this standard ranged between high and low levels. This result is due to the possibility of achieving benefits from physical activity through regular exercise .

The results of the sixth standard which is "Values to be gained by students through physical education" showed that the degree of application of the physical education teachers in the governorates (Jerash, Ajloun, and Mafraq) to the standard of "Values to be gained by students through physical education" was in a medium degree, and this result may be caused by the fact that the teacher understands the role of sports activity in achieving many values. In light of these comprehensive principles of the physical education curriculum, the overall results appeared in a medium degree, and this indicates the teachers' limited commitment to applying the physical education curricula as stated in the relevant Jordanian standards

Results related to the second study question, which stated "Are there statistically significant differences in the degree of the application of the Jordanian physical education curricula in light of the relevant Jordanian 
standards from the viewpoint of the teachers in the northern governorates of Jordan according to the variables of gender, years of experience, and academic qualification?

Table 4: The Arithmetic Mean and Standard Deviations for the Degree of Application of Physical Education

Curricula in the Light of the Jordanian Standard from the Point of View of Physical Education Teachers.

\begin{tabular}{|c|c|c|c|c|c|c|c|c|}
\hline \multirow[t]{2}{*}{ Variable } & \multirow[t]{2}{*}{$\begin{array}{l}\text { Levels } \\
\text { variables }\end{array}$} & \multirow[t]{2}{*}{ AM/SD } & \multicolumn{6}{|c|}{$\begin{array}{l}\text { The six Jordanian standards for physical education } \\
\text { curricula for the first and second grades }\end{array}$} \\
\hline & & & S1 & S2 & 3 & & S6 & \\
\hline \multirow[t]{4}{*}{ Gender } & \multirow[t]{2}{*}{ Male } & $\mathrm{AM}$ & 2.89 & 2.75 & 2.78 & 3.41 & 3.47 & 3.47 \\
\hline & & $\mathrm{SD}$ & 0.32 & 0.23 & 0.16 & 0.26 & 0.21 & 0.21 \\
\hline & \multirow[t]{2}{*}{ Female } & $\mathrm{AM}$ & 2.92 & 2.76 & 2.75 & 3.35 & 3.45 & 3.45 \\
\hline & & $\mathrm{SD}$ & 0.24 & 0.19 & 0.23 & 0.18 & 0.28 & 0.28 \\
\hline \multirow{4}{*}{$\begin{array}{ll}\text { Years } & \text { of } \\
\text { experience }\end{array}$} & \multirow{2}{*}{$\begin{array}{l}1 \text {-Less than } 5 \\
\text { years }\end{array}$} & $\mathrm{AM}$ & 2.89 & 2.79 & 2.75 & 3.39 & 3.42 & 3.42 \\
\hline & & $\mathrm{SD}$ & 0.35 & 0.21 & 0.29 & 0.16 & 0.26 & 0.26 \\
\hline & \multirow[t]{2}{*}{$5-10$ years } & $\mathrm{AM}$ & 2.90 & 2.71 & 2.80 & 3.42 & 3.47 & 3.47 \\
\hline & & $\mathrm{SD}$ & 0.20 & 0.32 & 0.22 & 0.25 & 0.18 & 0.18 \\
\hline \multirow{6}{*}{$\begin{array}{l}\text { Academic } \\
\text { qualification }\end{array}$} & \multirow{2}{*}{$\begin{array}{l}\text { More than } 10 \\
\text { years }\end{array}$} & AM & 2.94 & 2.77 & 2.73 & 3.31 & 3.46 & 3.46 \\
\hline & & $\mathrm{SD}$ & 0.21 & 0.19 & 0.23 & 0.25 & 0.27 & 0.27 \\
\hline & \multirow{2}{*}{$\begin{array}{l}\text { Bachelor and } \\
\text { below }\end{array}$} & $\mathrm{AM}$ & 2.90 & 2.75 & 2.74 & 3.34 & 3.46 & 3.46 \\
\hline & & $\mathrm{SD}$ & 0.24 & 0.21 & 0.19 & 0.23 & 0.25 & 0.25 \\
\hline & \multirow[t]{2}{*}{ Postgraduate } & AM & 3.02 & 2.78 & 2.85 & 3.50 & 3.39 & 3.39 \\
\hline & & SD & 0.20 & 0.16 & 0.31 & 0.21 & 0.24 & 0.30 \\
\hline
\end{tabular}

Table (4) showed an apparent variation in arithmetic means and standard deviations for the degree of application of the physical education teachers of the first and second grades for the skills and concepts included in the relevant Jordanian standards for physical education curricula for the first and second grades from their point of view and the dimensions related to it due to the difference in the categories of gender variables (male, female), academic qualification (Bachelor and below, postgraduate studies), and years of experience (1- less than 5 years, 5--10 years, more than 10 years). To explain the significance of the statistical differences among the arithmetic means, the multiple triple variance analysis was used on these areas as shown in a table (4).

Table 5: Analysis of Multiple Triple Variance of Study Variables according to the Application of Physical Education Curricula from the Viewpoint of Teachers of the Northern Governorates in Jordan.

\begin{tabular}{|c|c|c|c|c|c|c|}
\hline $\begin{array}{l}\text { Source of } \\
\text { variance }\end{array}$ & 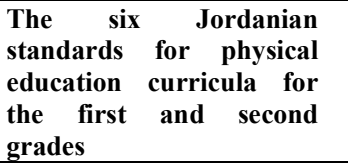 & $\begin{array}{l}\text { Sum of } \\
\text { squares }\end{array}$ & $\begin{array}{l}\text { Degrees of } \\
\text { freedom }\end{array}$ & $\begin{array}{l}\text { Average } \\
\text { of } \\
\text { squares }\end{array}$ & $\begin{array}{l}\text { Value of } \\
\text { F }\end{array}$ & $\begin{array}{l}\text { Statistical } \\
\text { significance }\end{array}$ \\
\hline \multirow{6}{*}{$\begin{array}{l}\text { Gender } \\
\text { Hoteling }=.056 \\
\mathrm{H}=736 .\end{array}$} & $\begin{array}{l}\text { Proficiency in basic motor } \\
\text { skills. }\end{array}$ & 0.010 & 1 & 0.010 & 0.181 & 0.672 \\
\hline & $\begin{array}{l}\text { Understanding motor skills } \\
\text { and principles }\end{array}$ & 0.048 & 1 & 0.048 & 1.193 & 0.279 \\
\hline & $\begin{array}{l}\text { Regular physical sport } \\
\text { activity }\end{array}$ & 0.078 & 1 & 0.078 & 1.457 & 0.232 \\
\hline & $\begin{array}{l}\text { Physical fitness to maintain a } \\
\text { high and continuous level of } \\
\text { health }\end{array}$ & 0.004 & 1 & 0.004 & 0.075 & 0.785 \\
\hline & $\begin{array}{l}\text { Demonstrate personal and } \\
\text { social behavior }\end{array}$ & 0.001 & 1 & 0.001 & 0.022 & 0.883 \\
\hline & $\begin{array}{l}\text { Values to be gained by } \\
\text { students through physical } \\
\text { education }\end{array}$ & 0.002 & 1 & 0.002 & 0.013 & 0.909 \\
\hline \multirow{6}{*}{$\begin{array}{l}\text { Years of } \\
\text { Experience } \\
\text { Wilkes = 478. } \\
\mathrm{H}=041 .\end{array}$} & $\begin{array}{l}\text { Proficiency in basic motor } \\
\text { skills. }\end{array}$ & 0.345 & 2 & 0.172 & 3.045 & $\underline{0.034^{*}}$ \\
\hline & $\begin{array}{l}\text { Understanding motor skills } \\
\text { and principles }\end{array}$ & 0.260 & 2 & 0.130 & 3.236 & 0.145 \\
\hline & $\begin{array}{lll}\begin{array}{l}\text { Regular physical sport } \\
\text { activity }\end{array} & \\
\end{array}$ & 0.164 & 2 & 0.082 & 1.523 & 0.232 \\
\hline & $\begin{array}{l}\text { Physical fitness to maintain a } \\
\text { high and continuous level of } \\
\text { health }\end{array}$ & 0.035 & 2 & 0.017 & 0.321 & 0.785 \\
\hline & $\begin{array}{l}\text { Demonstrate personal and } \\
\text { social behavior }\end{array}$ & 0.037 & 2 & 0.018 & 0.271 & $\underline{0.044^{*}}$ \\
\hline & $\begin{array}{l}\text { Values to be gained by } \\
\text { students through physical } \\
\text { education }\end{array}$ & 0.026 & 2 & 0.013 & 0.091 & $\underline{0.013 *}$ \\
\hline
\end{tabular}




\begin{tabular}{|c|c|c|c|c|c|c|}
\hline \multirow{6}{*}{$\begin{array}{l}\text { Academic } \\
\text { Qualification } \\
\text { Hotelling = 187. } \\
\text { H= 039. }\end{array}$} & $\begin{array}{l}\text { Proficiency in basic motor } \\
\text { skills. }\end{array}$ & 0.310 & 1 & 0.310 & 5.482 & $\underline{0.022 *}$ \\
\hline & $\begin{array}{l}\text { Understanding motor skills } \\
\text { and principles }\end{array}$ & 0.029 & 1 & 0.029 & 0.726 & 0.397 \\
\hline & $\begin{array}{lll}\begin{array}{l}\text { Regular } \\
\text { activity }\end{array} & \text { physical } & \text { sport } \\
\end{array}$ & 0.046 & 1 & 0.046 & 0.856 & $\underline{0.048^{*}}$ \\
\hline & $\begin{array}{l}\text { Physical fitness to maintain a } \\
\text { high and continuous level of } \\
\text { health }\end{array}$ & 0.242 & 1 & 0.242 & 4.493 & $\underline{0.038^{*}}$ \\
\hline & $\begin{array}{l}\text { Demonstrate personal and } \\
\text { social behavior }\end{array}$ & 0.033 & 1 & 0.033 & 0.485 & 0.488 \\
\hline & $\begin{array}{l}\text { Values to be gained by } \\
\text { students through physical } \\
\text { education }\end{array}$ & 0.115 & 1 & 0.115 & 0.805 & 0.373 \\
\hline \multirow[t]{6}{*}{ Error } & $\begin{array}{l}\text { Proficiency in basic motor } \\
\text { skills. }\end{array}$ & 3.848 & 0.057 & 0.057 & & \\
\hline & $\begin{array}{l}\text { Understanding motor skills } \\
\text { and principles }\end{array}$ & 2.736 & 0.040 & 0.040 & & \\
\hline & $\begin{array}{lll}\begin{array}{l}\text { Regular } \\
\text { activity }\end{array} & \text { physical } & \text { sport } \\
\end{array}$ & 3.656 & 0.054 & 0.054 & & \\
\hline & $\begin{array}{l}\text { Physical fitness to maintain a } \\
\text { high and continuous level of } \\
\text { health }\end{array}$ & 3.662 & 0.054 & 0.054 & & \\
\hline & $\begin{array}{l}\text { Demonstrate personal and } \\
\text { social behavior }\end{array}$ & 4.622 & 0.068 & 0.068 & & \\
\hline & $\begin{array}{l}\text { Values to be gained by } \\
\text { students through physical } \\
\text { education }\end{array}$ & 9.695 & 0.143 & 0.143 & & \\
\hline \multirow[t]{6}{*}{$\begin{array}{ll}\text { Sum } & \text { of } \\
\text { averages } & \end{array}$} & $\begin{array}{l}\text { Proficiency in basic motor } \\
\text { skills. }\end{array}$ & 4.482 & 78 & & & \\
\hline & $\begin{array}{l}\text { Understanding motor skills } \\
\text { and principles }\end{array}$ & 3.261 & 78 & & & \\
\hline & $\begin{array}{lll}\begin{array}{l}\text { Regular physical sport } \\
\text { activity }\end{array} & \\
\end{array}$ & 4.139 & 78 & & & \\
\hline & $\begin{array}{l}\text { Physical fitness to maintain a } \\
\text { high and continuous level of } \\
\text { health }\end{array}$ & 4.237 & 78 & & & \\
\hline & $\begin{array}{l}\text { Demonstrate personal and } \\
\text { social behavior }\end{array}$ & 4.834 & 78 & & & \\
\hline & $\begin{array}{l}\text { Values to be gained by } \\
\text { students through physical } \\
\text { education }\end{array}$ & 11.076 & 78 & & & \\
\hline
\end{tabular}

\section{*Significance at the degree of significance $(\alpha \geq 0.05)$.}

Table (5) showed that there are no statistically significant differences $(\boldsymbol{\alpha} \geq \mathbf{0 . 0 5})$ due to the effect of gender on all six standards, as well as the presence of statistically significant differences according to the variable of the academic qualification on the three standards "Proficiency in basic motor skills, Regular physical sport activity, and Physical fitness to maintain a high and continuous level of health" in favor of the (Postgraduate) category compared to the (BA) category according to their arithmetic means. There are also statistically significant differences $(\boldsymbol{\alpha} \geq \mathbf{0 . 0 5})$ due to the effect of years of experience on the three standards "Proficiency in basic motor skills, Demonstrate personal and social behavior, and Values to be gained by students through physical education. To know the significance of the differences among the categories of the variable, the Scheffe test has been used as shown in table (5). 
Table 6: Using the Scheffe Test for the Effect of Years of Experience with a Degree of Application on Physical Education Curricula from the Viewpoint of Teachers of the Northern Governorates in Jordan

\begin{tabular}{|l|l|l|l|l|}
\hline \multirow{2}{*}{ Areas } & $\begin{array}{l}\text { Variable } \\
\text { Categories }\end{array}$ & \multicolumn{1}{|c|}{ Less than 5 } & $\begin{array}{l}\mathbf{5}-\mathbf{1 0} \\
\text { years }\end{array}$ & $\begin{array}{l}\text { More than } \\
\mathbf{1 0} \text { years }\end{array}$ \\
\hline \multirow{4}{*}{ Proficiency in basic motor skills } & AM & 2.89 & 2.90 & 2.94 \\
\cline { 2 - 5 } & $1-$ To less than5 & - & 0.010 & $0.051^{*}$ \\
\cline { 2 - 5 } & $5-10$ years & - & - & $0.041^{*}$ \\
\hline \multirow{2}{*}{$\begin{array}{l}\text { Demonstrate personal and social } \\
\text { behavior }\end{array}$} & $\mathrm{AM}$ & 3.42 & 3.47 & 3.46 \\
\cline { 2 - 5 } & $1-$ To less than5 & - & $0.045^{*}$ & $0.04^{*}$ \\
\cline { 2 - 5 } & $5-10$ years & - & - & 0.006 \\
\hline \multirow{2}{*}{$\begin{array}{l}\text { Values to be gained by students } \\
\text { through physical education }\end{array}$} & AM & 2.20 & 2.41 & 2.40 \\
\cline { 2 - 5 } & $1-$ To less than5 & - & $0.213^{*}$ & $-0.203^{*}$ \\
\cline { 2 - 5 } & $5-10$ years & -- & -- & 0.01 \\
\hline
\end{tabular}

*Significance at the degree of significance $(\alpha \geq 0.05)$.

Table 6 indicates the presence of statistically significant differences according to the variable of year of experience on the standard of "Proficiency in basic motor skills" in favor of the higher experience category (10 years and more) compared to the categories (5-10 years and less than 5 years), as well as the presence of differences with statistical significance according to the variable of years of experience on the standard of "Demonstrate personal and social behavior" in favor of the two higher experience categories (10 years and more and the 5-10 years category) compared to the least experience category (less than 5 years). There are also statistically significant differences according to the variable of years of experience on the standard " Values to be gained by students through physical education" in favor of the two highest levels of years of experience (10 years and more and 5-10 years) compared to the least category of years of experience (less than 5 years).

In the light of the variables of the study, the researchers extrapolated it as follows: in the gender variable, there are no differences among them, and this result is due to the fact that there is no difference between a male teacher and a female teacher in applying the lessons because the one who leads them is the curriculum. Likewise, according to the variable of the academic qualification, there are three standards "Proficiency in basic motor skills, Regular physical sports activity, and Physical fitness to maintain a high and continuous level of health" in favor of the postgraduate degree category comparison to a Bachelor's degree category according to their means. Perhaps this result is due to the fact that when the teacher raises his educational level, he becomes more aware and more understanding of the goals of physical education in education, and thus keen to achieve them. Also, there are differences according to the years of experience variable on the standard of "Proficiency in basic motor skills" in favor of the higher experience category (10 years or more) compared to the two categories (5-10 years and less than 5 years), and this result may be caused by the fact that experience helps the teacher have a previous knowledge on students 'needs and focus more on improving students' level in skill application.

There are also differences according to the variable of years of experience on the standard of "Demonstrating personal and social behavior" in favor of the two higher experience categories (10 years or more and the 5-10 years category) compared to the lesser experience category (less than 5 years). This result may be due to the fact that experience helps to understand students' behaviors more and ensure personal and social behaviors in physical education lessons. There are also differences according to the variable of years of experience on the standard "Values to be gained by students through physical education" in favor of the two higher experience categories (10 years or more, and the 5-10 years category) compared to the lesser experience category (less than 5 years). This result may be caused by the fact that experience stimulates the teacher to focus on providing students with values because of their importance.

\section{Conclusion}

In light of the aforesaid discussion, the following has been concluded:

- There is a lack in the application of Jordanian physical education curricula in light of the content of international standards from the viewpoint of physical education teachers.

- Most experienced teachers are the most capable of applying Jordanian physical education curricula in the light of the content of Jordanian standards compared to bachelor's degree teachers. In contrast, there are no differences because of the gender variable in the application of Jordanian physical education curricula in light of the content of Jordanian standards from their point of view.

\section{Recommendations}

In light of the aforesaid conclusion, the following has been recommended:

- Train teachers on physical education curricula that include Jordanian standards for the first and second basic grades. 
- Urge teachers to adhere to the application of education curricula in accordance with Jordanian standards for basic first and second grades in light of the study results.

- $\quad$ Conduct similar important studies on the rest of the physical education guidebooks for other grades.

\section{References}

Abdulbasit, Sdeeq and Mustafa, Mohamed. (2008). Suggested academic standards for the content of physical education curricula in primary education in light of the quality of education, Egypt.

Backman, E. (2010), A Contribution To Equity And Democracy In Swedish Physical Education? An Analysis Of Codes In Swedish Physical Education Curricula, Curriculum Studies, 43(2), 269-288.

Educational Development Conference. (EDC, 2015).

Faraji, Saif (2015). Evaluation of the physical education curriculum for middle school in Iraq from the teachers' point of view in Anbar governorate. Master Thesis, Al Al-Bayt University, Jordan.

Harris, J. (2015), Influences on the Expression of Health within Physical Education Curricula in Secondary Schools in England and Wales, Sport, Education and Society, 20(7), p908-923.

Hawamdeh, Muhammad. (2007). Evaluation of the physical education curriculum for the upper basic stage from the teachers' point of view in the northern territory. Unpublished Master Thesis, Amman Arab University for Graduate Studies, Jordan.

Hussein, Abdul-Salam. (2011). Evaluation of the curricula of group games in the light of comprehensive quality programs and their relationship to educational values. Dirasat Journal, 2, 10-22.

Jarrah, Youssef. (2007). An evaluation study of the curricula of physical education developed from the viewpoint of teachers in Irbid. Unpublished master's thesis, Yarmouk University, Jordan.

Kilborn, M. (2016), An Analysis of Canadian Physical Education Curricula, European Physical Education Review, 22(1), p23-46.

Mahrous, Mahrous. (2017). Studies and applied research in the curricula and teaching of physical education, Sohag University, Dar Al-Wafaa for the world of printing, Alexandria, Egypt.

M. Michael (2017). Instructional Models For Physical Education, Georgia State University, Third Edition Palmade, G (2001). Les Mehodes En Pedagogie. Oueidat Beyrouth, Paris.

Physical Education Standards...... OSSE ( 2019). (Dc Office Of The State Superintendent Of Education.

Saeedi, Abdullah and Hussein, Abdul Salam. (2018). The degree to which physical education teachers possess the cognitive competencies associated with modern physical education curricula in the State of Kuwait, Journal of Educational Sciences Studies, 4, 13-27.

Tiffany, K. (2012), Teacher Evaluations of Standardized Physical Education Curricula, The Phystci J Hducuor, 69(1), 1- 19.

Zameem, Hussein. (2012). Evaluation of the physical and mathematical education curriculum for the first three students in the republic of Yemen. Unpublished Master Thesis, Yemen. 